\title{
$\$$ Research Square

\section{Low-Temperature Synthesis, Structural and Optical Characterizations of The Novel Bisbs3 Thin Films as Anew Absorber Layer for Solar Cells}

I M El radaf ( $\nabla$ eslam11b@gmail.com )

National research center https://orcid.org/0000-0001-6197-5272

H.Y.S Al-Zahrani

King Abdulaziz University Faculty of Sciences

\section{Research Article}

Keywords: BiSbS3, chemical bath deposition technique, XRD, extinction coefficient, optical free carrier concentration, nonlinear refractive index.

Posted Date: October 22nd, 2021

DOI: https://doi.org/10.21203/rs.3.rs-980800/v1

License: (c) (i) This work is licensed under a Creative Commons Attribution 4.0 International License.

Read Full License

Version of Record: A version of this preprint was published at Physica B: Condensed Matter on February 8th, 2022. See the published version at https://doi.org/10.1016/j.physb.2021.413655. 


\title{
Original Research Article
}

Low-Temperature Synthesis, Structural and Optical Characterizations of The Novel Bisbs 3 Thin Films as Anew Absorber Layer for Solar Cells

\author{
I. M. El Radaf ${ }^{1,2, *}$, H.Y.S Al-Zahrani ${ }^{3}$ \\ ${ }^{1}$ Materials Physics and Energy Laboratory, College of Sciences and Art at ArRass - Qassim University, \\ ArRass 51921, Kingdom of Saudi Arabia. \\ ${ }^{2}$ Electron Microscope and Thin Films Department, Physics Division, National Research Centre, Dokki, Giza \\ 12622, Egypt, Affiliation ID: 60014618. \\ ${ }^{3}$ King Abdulaziz University, College of Science\& Arts, Physics Department, Rabigh, Saudi Arabia. \\ *E-mail of corresponding author: elradaf11b@gmail.com;i.radaf@qu.edu.sa
}

\begin{abstract}
In this research work, thin films of $\mathrm{BiSbS}_{3}$ have been successfully synthesized onto well cleaned soda-lima glass substrates via the chemical bath deposition procedure at different thicknesses $(\mathrm{t}=159,243,296$ and $362 \mathrm{~nm})$. The X-ray diffraction patterns of the chemically deposited $\mathrm{BiSbS}_{3}$ films depicted that the synthesized films exposed polycrystalline nature and have an orthorhombic structure. The structural parameters of the chemically deposited $\mathrm{BiSbS}_{3}$ films were evaluated by Debye-Scherer's formulas. The surface morphologies of the $\mathrm{BiSbS}_{3}$ films were fixed via the fieldemission-scanning-electron microscope. The analyses of the linear optical parameters of the chemically deposited $\mathrm{BiSbS}_{3}$ thin films refer to improving the values of the absorption coefficient, $\alpha$ and the linear refractive index, $n$ via the increase in the film thickness. In addition, there is an observed reduction in the energy gap, $E_{g}$ values from 1.38 to $1.22 \mathrm{eV}$ occurred by raising the film thickness. Furthermore, there is an enhancement in the nonlinear optical constants and the optoelectrical parameters occurred by raising the film thickness where the nonlinear refractive index, $n_{2}$, the optical free carrier concentration, $N_{o p t}$ and the optical conductivity $\sigma_{o p t}$ were enlarged with increasing the values of film thickness. Moreover, the hot probe procedure was applied to the $\mathrm{BiSbS}_{3}$ thin films and this method demonstrated that the chemically deposited $\mathrm{BiSbS}_{3}$ films are p-type semiconductors.
\end{abstract}

Keywords: $\mathrm{BiSbS}_{3}$; chemical bath deposition technique; XRD; extinction coefficient; optical free carrier concentration; nonlinear refractive index.

\section{Introduction}

Recently, binary and ternary chalcogenide thin films attract vast attention in recent time owing to their high refractive index, absorption coefficient and suitable band gap energy (Akande et al. 2020; 
Jia et al. 2020; Yang et al. 2021a). So, the binary and ternary chalcogenide thin films are widely suitable for various applications like memories, light-emitting diode, solar cells, semiconductor devices, transistors and computer chips (Wang et al. 2020b; Xie et al. 2021; Zhang et al. 2020). The binary chalcogenide (B.C) thin films like $\mathrm{CdS}, \mathrm{Sb}_{2} \mathrm{~S}_{3}, \mathrm{SnS}, \mathrm{ZnS}$ and CdTe are important semiconductor materials that exhibited better performance in thin film solar cells (Eensalu et al. 2022; Jrad et al. 2021; Rahman et al. 2021; Sharma et al. 2021). ZnS and CdS thin films are important window layers for thin film solar cells due to these films characterized by n-type conductivity, high optical transmittance and wide bandgap ranged from $3 \mathrm{eV}$ to $3.8 \mathrm{eV}$ (Kathalingam et al. 2021; Shakoury et al. 2020). Moreover, the $\mathrm{Sb}_{2} \mathrm{~S}_{3}$, $\mathrm{SnS}$ and CdTe are important p-type semiconductors characterized by p-type conductivity, high absorption coefficient and narrow bandgap ranged from $1.2 \mathrm{eV}$ to $1.5 \mathrm{eV}$ So, these films are suitable for producing convenient absorber layer for thin film solar cells (Javed et al. 2020; Rahman et al. 2020; Yang et al. 2021b).

The ternary chalcogenide (T.C) thin films such as $\mathrm{CuSbS}_{2}, \mathrm{Cu}_{3} \mathrm{SnS}_{3}, \mathrm{CuInS}_{2}, \mathrm{ZnAl}_{2} \mathrm{~S}_{4}$ and $\mathrm{CdAl}_{2} \mathrm{~S}_{4}$ are impressive optical materials due to their high absorption coefficient, linear and nonlinear refractive indices (Nagamalleswari et al. 2021; Yang et al. 2020). $\mathrm{CuSbS}_{2}, \mathrm{Cu}_{3} \mathrm{SnS}_{3}, \mathrm{CuInS}_{2}$ ternary films were used as an absorber layer for thin film solar cells due to these films exhibited narrow bandgap ranged from $1.5 \mathrm{eV}$ to $1.7 \mathrm{eV}$, p-type conductivity and high absorption coefficient (Sawant et al. 2021; Vinayakumar et al. 2017). On the other hand, $\mathrm{ZnAl}_{2} \mathrm{~S}_{4}$ and $\mathrm{CdGa}_{2} \mathrm{~S}_{4}$ thin films are important n-type semiconductors characterized by high optical transmittance, $n$-type conductivity and wide bandgap ranged from $3 \mathrm{eV}$ to $3.8 \mathrm{eV}$. So, these films are suitable for producing a good window layer for thin film solar cells (Kumar et al. 2017; El Radaf et al. 2020b). The experimental procedures of synthesized the binary and ternary chalcogenide thin films were classified into two categories. They are the chemical techniques like spray pyrolysis (Thangaraju and Kaliannan 2000), chemical bath deposition (Mane and Lokhande 2000) and electro-deposition (Manivannan and Victoria 2018) technique. While the vacuum techniques include sputtering (Verger et al. 2013), thermal evaporation (Orava et al. 2014) and flash evaporation techniques (Merino et al. 2000).

Among binary chalcogenides the antimony chalcogenides. The Sb-S and their ternary systems like $\mathrm{Cu}-\mathrm{Sb}-\mathrm{S}, \mathrm{Sn}-\mathrm{Sb}-\mathrm{S}, \mathrm{In}-\mathrm{Sb}-\mathrm{S}$ and $\mathrm{Bi}-\mathrm{Sb}-\mathrm{S}$ are important materials that received considerable attention in different articles owing to these materials are earth-abundant, inexpensive, non-toxic and have good electrical and optical properties (Bennaji et al. 2018; Maiti et al. 2019). Many articles focused on studying the physical properties of the $\mathrm{CuSbS}_{2}, \mathrm{CuSbSe}_{2}$ and $\mathrm{SnSb}_{2} \mathrm{~S}_{4}$ thin films due to these films characterized by high values of absorption coefficient, ease of preparation, p-type conductivity and narrow bandgap energy. The $\mathrm{BiSbS}_{3}$ is a novel semiconductor material that has excellent electrochemical performance, good thermoelectric properties and high specific capacity 
(Patra et al. 2017; Wang et al. 2020a; Wen et al. 2019). The previous article focused on preparing the $\mathrm{BiSbS}_{3}$ in the nanorods form by the hydrothermal method (Wen et al. 2019). On the other side, no article presents the synthesis and characterization of the $\mathrm{BiSbS}_{3}$ thin films. So in the present work aims to synthesis the novel $\mathrm{BiSbS}_{3}$ thin films for the first time by the cost-effective chemical bath deposition technique. The authors have tried to fabricate the chemically deposited $\mathrm{BiSbS}_{3}$ film with good quality to study the structural and optical properties of $\mathrm{BiSbS}_{3}$ films. Then, the authors have discussed some optoelectrical parameters, the linear and nonlinear optical parameters of the chemically deposited $\mathrm{BiSbS}_{3}$ films.

\section{Materials and characterizations}

\subsection{Preparation of the $\mathrm{BiSbS}_{3}$ thin films}

$\mathrm{BiSbS}_{3}$ films were synthesized at room temperature on precleaned soda-lima glass substrates by an inexpensive chemical bath deposition procedure. To obtain different film thicknesses, we prepare the $\mathrm{BiSbS}_{3}$ thin films at several deposition times 1, 3, 5, 7 hours. High purity chemical salts have been used to synthesize the $\mathrm{BiSbS}_{3}$ solution like antimony chloride $\left(\mathrm{SbCl}_{3}\right)$ Sigma-Aldrich with purity degrees (99.99\%), sodium thiosulfate $\left(\mathrm{Na}_{2} \mathrm{~S}_{2} \mathrm{O}_{3}\right)$ Sigma-Aldrich with purity degrees (99.99\%) and bismuth nitrate $\left(\mathrm{BiNO}_{3}\right)$ Sigma-Aldrich with purity degrees (99.99\%). The $\mathrm{BiSbS}_{3}$ precursor solution was synthesized by the interaction between: (i) $1 \mathrm{M}$ antimony chloride $\left(\mathrm{SbCl}_{3}\right)$ was dissolved in $5 \mathrm{ml}$ acetone. (ii) $1 \mathrm{M}$ sodium thiosulfate $\left(\mathrm{Na}_{2} \mathrm{~S}_{2} \mathrm{O}_{3}\right)$ was dissolved in $25 \mathrm{ml}$ deionized water. (iii) $1 \mathrm{M}$ bismuth nitrate $\left(\mathrm{BiNO}_{3}\right)$ was dissolved in $10 \mathrm{ml}$ diluted Nitric acid. The $\mathrm{BiSbS}_{3}$ solution was stirred well for 30 minutes to produce a brown solution. Then the cleaned glass slides were placed in the BiSbS$_{3}$ solution at different deposition times 1, 3, 5 and 7 hours to get thin films of different thicknesses. At the finish of the deposition time, the $\mathrm{BiSbS}_{3}$ thin films were extracted from the chemical bath and washed well with the deionized water and after this the $\mathrm{BiSbS}_{3}$ films were dried in air.

\subsection{Characterization of the $\mathrm{BiSbS}_{3}$ thin films}

The thickness of the $\mathrm{BiSbS}_{3}$ samples was determined by stylus profiler type (Dektak 150 surface profiler) and the values of the thickness for the $\mathrm{BiSbS}_{3}$ samples equal 159, 243, 296 and 362 $\mathrm{nm}$. The surface morphological features and the compositional element percentages of the chemically deposited $\mathrm{BiSbS}_{3}$ samples deposited on the glass substrate were characterized via using the QuantaFeG-250 USA field emission scanning electron microscope (FE-SEM). The X-ray diffraction (XRD) data of the chemically deposited $\mathrm{BiSbS}_{3}$ samples were examined using a Philips-X'Pert X-ray diffractometer, with $\mathrm{CuK}_{\alpha}$ radiation. The optical properties of the $\mathrm{BiSbS}_{3}$ films were inspected via measuring the reflectance, $R$ and transmittance, $T$ of the films in the wavelength ranged from $400 \mathrm{~nm}$ to $2500 \mathrm{~nm}$ using UV-Visible spectrophotometer, JASCO (V-570.). 


\section{Results and discussions}

\subsection{Structural analysis}

The X-ray investigations of the $\mathrm{BiSbS}_{3}$ films with various thicknesses $(\mathrm{t}=159,243,296$ and $362 \mathrm{~nm}$ ) were presented in Fig.1. It can be deduced from this pattern that the presence of three diffraction peaks at $25.15^{\circ}, 42.57^{\circ}$, and $51.35^{\circ}$ positions corresponding to the planes $(012),(311)$ and (024). The observed peaks of all films show the formation of the orthorhombic phase of the BiSbS3 which is in good agreement with the Standard ICSD No. 617029 (Wen et al. 2019).

Herein the structural parameters of the chemically deposited $\mathrm{BiSbS}_{3}$ films can be obtained using Debye-Scherer's formulas. The crystallite size $(D)$ and the dislocation density $(\delta)$ of the chemically deposited $\mathrm{BiSbS}_{3}$ films were computed according to the following equations (Hassanien and El Radaf 2020; Liu et al. 2021):

$D=\frac{0.9 \lambda}{\beta \cos \theta}$

$\delta=\frac{1}{D^{2}}$

Here $\theta$ represent the Bragg diffraction angle and $\beta$ denotes the experimental full-width corresponding to the half maximum (FWHM).

On the other hand, the micro-strain values $(\varepsilon)$ and the number of crystallites per unit surface area values ( $N_{C}$ of the chemically deposited $\mathrm{BiSbS}_{3}$ films was calculated by the formulas (Akl et al. 2021; Akl and Hassanien 2021):

$$
\begin{aligned}
& N_{C}=\frac{t}{D^{3}} \\
& \varepsilon_{s}=\frac{\beta \cos (\theta)}{4}
\end{aligned}
$$

Here $t$ denotes the thickness of the chemically deposited $\mathrm{BiSbS}_{3}$ films.

Table 1 display the magnitudes of the structure parameters $D, \delta, N_{C}$ and $\varepsilon_{S}$ of the chemically deposited $\mathrm{BiSbS}_{3}$ films. It can be observed from this table that there is a reduction in the $\delta, N_{C}$ and $\varepsilon_{S}$ values occurred by rising the thickness of the chemically prepared $\mathrm{BiSbS}_{3}$ films and there is an increase in the $D$ values occurred by rising the thickness of the investigated films. The dependence of $D$ and $N_{C}$ of the chemically deposited $\mathrm{BiSbS}_{3}$ films on the film thickness was depicted in Fig.2. It is observed from this figure that the $D$ values were enlarged with increasing the film thickness and the $N_{C}$ values were reduced with enlarging the film thickness.

\subsection{Morphological and compositional studies}


The FE SEM investigations of chemically deposited $\mathrm{BiSbS}_{3}$ films were presented in Fig. 3. We can see from this figure that the chemically deposited $\mathrm{BiSbS}_{3}$ film with thickness $159 \mathrm{~nm}$ has a homogenous surface consists of small grains as illustrated in Fig.3 (a). Moreover, the number and size of grains were increased by increasing the film thickness to $362 \mathrm{~nm}$ as displayed in Fig.3 (b). The EDAX result of the chemically deposited $\mathrm{BiSbS}_{3}$ films synthesized at various thicknesses $(\mathrm{t}=159,243$, 296 and $362 \mathrm{~nm}$ ) demonstrated that the $\mathrm{BiSbS}_{3}$ films exhibit a stoichiometric composition and the EDAX pattern display the existence of the $\mathrm{Bi}, \mathrm{Sb}$ and $\mathrm{S}$ peaks at their energy positions.

\subsection{Optical studies}

The linear optical parameters of the $\mathrm{BiSbS}_{3}$ films synthesized at various thicknesses $(\mathrm{t}=159$, 243, 296 and $362 \mathrm{~nm}$ ) have been computed from transmittance and the reflectance data in the wavelength ranged from 400 to $2500 \mathrm{~nm}$. Fig. 4 (a) and (b) depicted transmittance and the reflectance spectra of the chemically deposited $\mathrm{BiSbS}_{3}$ films synthesized at various thicknesses. It can be observed from this figure that transmittance values of the $\mathrm{BiSbS}_{3}$ films were reduced by raising the film thickness from $159 \mathrm{~nm}$ to $362 \mathrm{~nm}$. Also, the reflectance values of the chemically prepared $\mathrm{BiSbS}_{3}$ films were enlarged by raising the film thickness from $159 \mathrm{~nm}$ to $362 \mathrm{~nm}$. Thus, we calculate the absorption coefficient values of the $\mathrm{BiSbS}_{3}$ films synthesized at various thicknesses. The absorption coefficient is an important factor determine how far inside the material light of a particular wavelength is able on penetrating before it is absorbed. Various semiconductors have different values of absorption coefficients values. The materials have great values of absorption coefficients were easily absorb the photons, and these materials can excite the electrons to a conduction band. Determining the values of absorption coefficients of the semiconductor materials helps in detecting the best materials which can be used in the solar cell designs (Hassanien and Akl 2020).

The absorption coefficient values $(\alpha)$ of the chemically prepared $\mathrm{BiSbS}_{3}$ films can be calculated according to the formula (Shaban et al. 2016; Sharma et al. 2017):

$$
\alpha(\lambda)=\frac{1}{t} \operatorname{Ln}\left[\frac{(1-R)^{2}}{2 T}+\sqrt{\frac{(1-R)^{4}}{4 T^{2}}+R^{2}}\right]
$$

Here $t$ represents the film thickness.

Fig.5 (a) displays the plot of the absorption coefficient, $\alpha$ with the wavelength for the chemically prepared $\mathrm{BiSbS}_{3}$ films. From this plot, we can see that the $\alpha$ was enlarged with increasing the film thickness and the $\alpha$ of the chemically prepared $\mathrm{BiSbS}_{3}$ films have high values.

The energy gap values of the chemically prepared $\mathrm{BiSbS}_{3}$ films can be estimated according to Tauc's formula (Shi et al. 2018; Tauc et al. 1966): 
$\alpha \boldsymbol{h} v=Q\left(E-E_{g}\right)^{P}$

Here $E$ denotes the photon energy which equals $h v, Q$ represents a constant and $p$ is the number that illustrates the optical transition kind and it is having the value $1 / 2$ and 2 for the direct allowed and the indirect allowed optical transitions, respectively. In this work, the best fitting is obtained at $p=1 / 2$ which indicated the allowed direct optical transition.

Fig.5 (b) demonstrates the variation of the $(\alpha h v)^{2}$ versus $h v$ for the chemically prepared $\mathrm{BiSbS}_{3}$ films synthesized at various thicknesses. we can estimate the energy gap value of the $\mathrm{BiSbS}_{3}$ films from the intercept with the $x$-axis of this plot. Table 2 shows the $E_{g}$ values of the chemically deposited $\mathrm{BiSbS}_{3}$ films. It can be observed from this table that there is a reduction in the $E_{g}$ values occurred by rising the thickness of the $\mathrm{BiSbS}_{3}$ films from $159 \mathrm{~nm}$ to $362 \mathrm{~nm}$. This trend could be associated with the enlarging in structural defects which form localized states in the gap that resulting in reducing the bandgap value (Hassanien and Akl 2016).

On the other side, the Urbach's energy for the $\mathrm{BiSbS}_{3}$ films synthesized at various thicknesses was deduced according to the following relation (Alharbi et al. 2016; Hameed et al. 2019):

$\alpha=\alpha_{\mathrm{o}} \exp \left(\mathrm{hv} / \mathrm{E}_{e}\right)$

Fig. 6 (a) illustrates the variation of $\ln (\alpha)$ versus $h v$ for the chemically prepared $\mathrm{BiSbS}_{3}$ films of various thicknesses. It is seen from this figure that the Urbach's energy values of the investigated films were enlarged by enlarging the film thickness from $159 \mathrm{~nm}$ to $362 \mathrm{~nm}$. The magnitude of the $E_{e}$ for chemically prepared $\mathrm{BiSbS}_{3}$ films were recorded in table 2 . It can be observed from this table that the $E_{e}$ values of the $\mathrm{BiSbS}_{3}$ films were enlarged by rising the film thickness.

On the other side, the extinction coefficient $(k)$ of the $\mathrm{BiSbS}_{3}$ films can be evaluated using the following relationship (Ganesh et al. 2017):

$K=\frac{\alpha \lambda}{4 \pi}$

Fig. 6 (b) displays the variations of $k$ for the chemically prepared $\mathrm{BiSbS}_{3}$ films as a function of the wavelength. It can be observed that the values of $k$ were enlarged by raising the film thickness from $159 \mathrm{~nm}$ to $362 \mathrm{~nm}$.

The refractive index values $(n)$ of the chemically prepared $\mathrm{BiSbS}_{3}$ films have been computed according to Kramer's - Kroning relationship (Elsaeedy 2019; Hosni et al. 2006):

$n=\frac{1+R}{1-R}+\left(\frac{4 R}{(1-R)^{2}}-k^{2}\right)^{1 / 2}$ 
Fig.7 (a) illustrated the reliance of the $n$ with $\lambda$ for the chemically prepared $\mathrm{BiSbS}_{3}$ films of various thicknesses. The refractive index values of the chemically prepared $\mathrm{BiSbS}_{3}$ films were increased by raising the film thickness from $159 \mathrm{~nm}$ to $362 \mathrm{~nm}$. This performance displays a close agreement with the contribution of the electronic transition in the chemically prepared $\mathrm{BiSbS}_{3}$ films.

Moreover, dispersion parameters of the chemically prepared $\mathrm{BiSbS}_{3}$ films like the values of single oscillator energy $\left(E_{o}\right)$ and the values of dispersion energy $\left(E_{d}\right)$ have been calculated by the Wemple-DiDomenico model according to the following relationship (Wemple 1973; Wemple and DiDomenico Jr 1971):

$n^{2}=1+\frac{E_{o} E_{d}}{E_{o}^{2}-(h v)^{2}}$

The variation of the $\left(n^{2}-1\right)^{-1}$ versus $(\hbar v)^{2}$ for the chemically prepared $\mathrm{BiSbS}_{3}$ films is presented in Fig.7 (b). It is noted from this figure that the values of the $E_{o}$ and $E_{d}$ at different film thicknesses were estimated from the straight-lines slope and intercept that was fitted, as illustrated in Fig. 6 (b). The dependence of the $E_{o}$ and $E_{d}$ values on the thickness of the chemically prepared $\mathrm{BiSbS}_{3}$ films were displayed in Table 2. It is observed from this table that the $E_{d}$ values were enlarged with the rising in the film thickness and the $E_{o}$ values were decreased with the rising in the film thickness. Moreover, the oscillator strength $f$, the static refractive index $n_{o}$ and static high-frequency dielectric constant $\varepsilon_{S}$ of the chemically prepared $\mathrm{BiSbS}_{3}$ films were computed according to the following relationships (El-Nahass and Farag 2012; Hameed et al. 2018; Sharma and Katyal 2008):

$n_{o}=\sqrt{1+\frac{E_{d}}{E_{o}}}$

$f=E_{o} E_{d}$

$\varepsilon_{s}=n_{o}^{2}$

The values of the $f, n_{o}$, and $\varepsilon_{s}$ for the chemically prepared $\mathrm{BiSbS}_{3}$ films were recorded in Table 1 and it is observed that by enlarging the film thickness, the values of $n_{o}$, $f$ and $\varepsilon_{s}$ were enlarged.

\subsection{Optoelectrical parameters}

The optical properties of the semiconductor materials were expressed in terms of the complex dielectric function $\varepsilon=\varepsilon_{1}+i \varepsilon_{2}$. The real, $\varepsilon_{1}$, and imaginary, $\varepsilon_{2}$ parts of this description are both frequency-dependent quantities, which contain all the desired response information [53].

In this study, the values of $\varepsilon_{1}$ and $\varepsilon_{2}$ for the chemically prepared $\mathrm{BiSbS}_{3}$ films was deduced using the following formulas (Hassanien and Akl 2018; Hassanien and Sharma 2020): 
$\varepsilon_{1}=n^{2}-k^{2}$

$\varepsilon_{2}=2 n k$

Fig.8 (a) and (b) demonstrates the variations of $\varepsilon_{1}$ and $\varepsilon_{2}$ for the chemically prepared $\mathrm{BiSbS}_{3}$ films with the $\lambda$. The $\varepsilon_{1}$ and $\varepsilon_{2}$ values have been enlarged by increasing the film thickness.

The optical conductivity $\left(\sigma_{o p t}\right)$ is an important parameter that describes the conduction behavior of the investigated material which is created from the movement of charge carriers through the material (El Radaf et al. 2019). The magnitude of the optical conductivity $\left(\sigma_{o p t}\right)$ for the chemically prepared $\mathrm{BiSbS}_{3}$ films of various film thicknesses were deduced using the below relation (El Radaf et al. 2020a):

$\sigma_{\text {opt }}=\frac{\alpha n c}{4 \pi}$

Here $\alpha$ is the absorption coefficient, $c$ is the speed of light and $n$ denotes the refractive index.

Fig.9 (a) illustrates a plot of $\sigma_{\text {opt }}$ against $h v$ for the chemically prepared $\mathrm{BiSbS}_{3}$ films of various thicknesses. It can be seen that there is a gradual increase in the optical conductivity values that occurred with the increase in film thickness. This performance was related to the increasing of the charge carriers. Furthermore, the optical conductivity enlarged also with enlarging the incident photon energy. This trend owing to the increase in the excitation process of the electronic charges via rising the incident photon energy.

On the other side, the values of the lattice dielectric constant and the ratio of an optical free carrier concentration to effective mass $\left(N_{o p t} / m^{*}\right)$ can be evaluated according to this equation (AlKhalifah et al. 2020; El-Bana and Fouad 2017):

$n^{2}=\varepsilon_{L}-\left(\frac{e^{2}}{4 \pi^{2} c^{2} \varepsilon_{0}}\right)\left(\frac{N_{o p t}}{m^{*}}\right) \lambda^{2}$

Here $e$ represents the electronic charge, $c$ represents the speed of light and $\varepsilon_{o}$ is the electric permittivity of free space.

Fig.9 (b) demonstrated the variation of $n^{2}$ versus $\lambda^{2}$ for the chemically prepared $\mathrm{BiSbS}_{3}$ films. The magnitudes of the $\left(N_{o p t} / m^{*}\right)$ and $\varepsilon_{L}$ were evaluated from this plot and recorded in Table.2. It is noted that the values of $\varepsilon_{L}$ and $N_{o p t} / m^{*}$ were enlarged with growing the film thickness. This thickness enlargement is associated with the rise in the charge carrier concentration. This was related to the possibility of attaining a degree of ordering in the chemically prepared $\mathrm{BiSbS}_{3}$ films (Fouad et al. 2006).

\subsection{Nonlinear optical parameters}


The determining of the nonlinear optical constants of the chalcogenide films has a vital role in nonlinear optical devices like optical switching, optical signal processing and frequency doubling (Kasap and Capper 2017). Miller's relationships have been employed to deduce the first-order nonlinear susceptibility $\chi^{(1)}$, the magnitude of the nonlinear refractive index $n_{2}$ and the third-order nonlinear optical susceptibility, $\chi^{(3)}$ for the chemically prepared $\mathrm{BiSbS}_{3}$ films by (Darwish et al. 2017; Hassanien et al. 2021; Lougdali et al. 2021):

$$
\begin{aligned}
& \chi^{(1)}=\frac{n_{o}^{2}-1}{4 \pi} \\
& \chi^{(3)}=\frac{A\left(n_{o}^{2}-1\right)^{4}}{(4 \pi)^{4}} \\
& n_{2}=\frac{12 \pi \chi^{(3)}}{n_{o}}
\end{aligned}
$$

Where $n_{0}$, B denotes the static refractive index of the chemically prepared $\mathrm{BiSbS}_{3}$ films and a constant value, equals $1.7 \times 10^{-10}$ esu respectively.

The magnitude of the $\chi^{(1)}, \chi^{(3)}$ and $n_{2}$ for chemically prepared $\mathrm{BiSbS}_{3}$ films were listed in table 3. It is obvious that by enlarging the film thickness, both of the $\chi^{(1)}, \chi^{(3)}$ and $n_{2}$ were enlarged.

Fig. 10 illustrates the dependence of the $\chi^{(3)}$ and $n_{2}$ on the film thickness for the chemically prepared $\mathrm{BiSbS}_{3}$ films. It is observed that the magnitude of the $\chi^{(3)}$ and $n_{2}$ for the chemically prepared $\mathrm{BiSbS}_{3}$ films have been enlarged by rising the film thickness from $159 \mathrm{~nm}$ to $362 \mathrm{~nm}$.

\subsection{Detecting of the semiconductor kind}

To detect the semiconductor kind of the chemically prepared $\mathrm{BiSbS}_{3}$ thin films we apply the hot-probe procedure. In this experiment, the two probes were connected to a sensitive digital multimeter and we join the hot probe to the positive port and the cold probe was joined with the negative port as illustrated in Fig.11. This experiment demonstrated a negative voltage on the multimeter that detects a p-type semiconductor and in case of appearing positive voltage on the multimeter, it refers to the n-type semiconductor (Axelevitch and Golan 2013). The experiment shows negative voltage for all samples, which shows that the chemically prepared $\mathrm{BiSbS}_{3}$ films reveal the ptype conductivity.

\section{Conclusions}

In this study, $\mathrm{BiSbS}_{3}$ thin films were synthesized at room temperature on precleaned soda-lima glass substrates by an inexpensive chemical bath deposition procedure. The XRD of the chemically deposited $\mathrm{BiSbS}_{3}$ films indicated that the as-prepared $\mathrm{BiSbS}_{3}$ films exposed polycrystalline nature and 
have an orthorhombic structure. The structural parameters of the chemically deposited $\mathrm{BiSbS}_{3}$ films were evaluated by Debye-Scherer's formulas. The FE SEM investigation of chemically deposited $\mathrm{BiSbS}_{3}$ films displays that the investigated films have homogeneous surfaces and the EDAX pattern of the chemically deposited $\mathrm{BiSbS}_{3}$ films confirms a stoichiometric composition for the $\mathrm{BiSbS}_{3}$ films. The optical results show that the refractive index, $n$, absorption coefficient, $\alpha$ and the extinction coefficient, $k$ of the chemically prepared $\mathrm{BiSbS}_{3}$ films were enlarged with growing the film thickness. On the other side, the optical bandgap of the $\mathrm{BiSbS}_{3}$ films was reduced by increasing the film thickness. Moreover, the optoelectrical parameters of the chemically prepared $\mathrm{BiSbS}_{3}$ films like the optical conductivity $\left(\sigma_{o p t}\right)$ and the optical free carrier concentration to effective mass $\left(N_{o p t} / m^{*}\right)$ were enlarged with enlarging the film thickness. The non-linear optical constants $\chi^{(1)}, \chi^{(3)}$ and $n_{2}$ for the chemically prepared $\mathrm{BiSbS}_{3}$ films were enlarged by raising the film thickness. The hot-probe procedure shows that the chemically prepared $\mathrm{BiSbS}_{3}$ films reveal the p-type conductivity.

\section{Conflicts of interest}

The authors declare that they have no conflict of interest.

\section{References}

Akande, A., El-Mellouhi, F., Park, H., Sanvito, S.: Theoretical investigation of the structural, elastic, electronic, and dielectric properties of alkali-metal-based bismuth ternary chalcogenides. Phys. Rev. Mater. 4, 75401 (2020)

Akl, A.A., Hassanien, A.S.: Comparative microstructural studies using different methods: Effect of Cd-addition on crystallography, microstructural properties, and crystal imperfections of annealed nano-structural thin CdxZn1-xSe films. Phys. B Condens. Matter. 620, 413267 (2021)

Akl, A.A., El Radaf, I.M., Hassanien, A.S.: An extensive comparative study for microstructural properties and crystal imperfections of Novel sprayed Cu3SbSe3 Nanoparticle-thin films of different thicknesses. Optik (Stuttg). 227, 165837 (2021)

Alharbi, S.R., Darwish, A.A.A., Al Garni, S.E., ElSaeedy, H.I., El-Rahman, K.F.A.: Influence of thickness and annealing on linear and nonlinear optical properties of manganese (III) chloride tetraphenyl porphine (MnTPPCl) organic thin films. Infrared Phys. Technol. 78, 77-83 (2016)

AlKhalifah, M.S., El Radaf, I.M., El-Bana, M.S.: New window layer of Cu2CdSn3S8 for thin film solar cells. J. Alloys Compd. 813, 152169 (2020)

Axelevitch, A., Golan, G.: Hot-probe method for evaluation of majority charged carriers concentration in semiconductor thin films. Facta Univ. Electron. Energ. 26, 187-195 (2013)

Bennaji, N., Lahouli, R., Fadhli, Y., Mellouki, I., Kanzari, M., Khirouni, K., Yacoubi, N., Amlouk, M.: Tuning of the electrical and thermal properties of $\mathrm{SnSb2S} 4$ sulfosalt vacuum evaporated thin films subjected to a heat treatment for thermoelectric application. Sensors Actuators A Phys. 281, 67-75 (2018)

Darwish, A.A.A., Rashad, M., Bekheet, A.E., El-Nahass, M.M.: Linear and nonlinear optical properties of GeSe2-xSnx $(0 \leq x \leq 0.8)$ thin films for optoelectronic applications. J. Alloys Compd. 
709, 640-645 (2017)

Eensalu, J.S., Tõnsuaadu, K., Acik, I.O., Krunks, M.: Sb2S3 thin films by ultrasonic spray pyrolysis of antimony ethyl xanthate. Mater. Sci. Semicond. Process. 137, 106209 (2022)

El-Bana, M.S., Fouad, S.S.: Opto-electrical characterisation of As33Se67-xSnx thin films. J. Alloys Compd. 695, 1532-1538 (2017)

El-Nahass, M.M., Farag, A.A.M.: Structural, optical and dispersion characteristics of nanocrystalline GaN films prepared by MOVPE. Opt. Laser Technol. 44, 497-503 (2012)

Elsaeedy, H.I.: Growth, structure, optical and optoelectrical characterizations of the $\mathrm{Cu} 2 \mathrm{NiSnS} 4$ thin films synthesized by spray pyrolysis technique. J. Mater. Sci. Mater. Electron. 1-10 (2019)

Fouad, S.S., El-Shazly, E.A.A., Balboul, M.R., Fayek, S.A., El-Bana, M.S.: Optical parameter studies of thermally evaporated As-Se-Sn glassy system. J. Mater. Sci. Mater. Electron. 17, 193-198 (2006)

Ganesh, V., Yahia, I.S., AlFaify, S., Shkir, M.: Sn-doped ZnO nanocrystalline thin films with enhanced linear and nonlinear optical properties for optoelectronic applications. J. Phys. Chem. Solids. 100, 115-125 (2017)

Hameed, T.A., El Radaf, I.M., Sakr, G.B.: Synthesis and characterization of thermochromic Ag 2 HgI 4 thin films. Appl. Phys. A. 124, 684 (2018)

Hameed, T.A., Wassel, A.R., El Radaf, I.M.: Investigating the effect of thickness on the structural, morphological, optical and electrical properties of AgBiSe2 thin films. J. Alloys Compd. 805, 1-11 (2019). https://doi.org/10.1016/j.jallcom.2019.07.041

Hassanien, A.S., Akl, A.A.: Effect of Se addition on optical and electrical properties of chalcogenide CdSSe thin films. Superlattices Microstruct. 89, 153-169 (2016)

Hassanien, A.S., Akl, A.A.: Optical characteristics of iron oxide thin films prepared by spray pyrolysis technique at different substrate temperatures. Appl. Phys. A. 124, 752 (2018)

Hassanien, A.S., Akl, A.A.: Optical characterizations and refractive index dispersion parameters of annealed $\mathrm{TiO} 2$ thin films synthesized by RF-sputtering technique at different flow rates of the reactive oxygen gas. Phys. B Condens. Matter. 576, 411718 (2020)

Hassanien, A.S., El Radaf, I.M.: Optical characterizations of quaternary Cu2MnSnS4 thin films: Novel synthesis process of film samples by spray pyrolysis technique. Phys. B Condens. Matter. 585, 412110 (2020). https://doi.org/10.1016/j.physb.2020.412110

Hassanien, A.S., Sharma, I.: Optical properties of quaternary a-Ge15-x Sbx Se50 Te35 thermally evaporated thin-films: refractive index dispersion and single oscillator parameters. Optik (Stuttg). 200,163415 (2020)

Hassanien, A.S., Sharma, I., Aly, K.A.: Linear and nonlinear optical studies of thermally evaporated chalcogenide a-Pb-Se-Ge thin films. Phys. B Condens. Matter. 613, 412985 (2021)

Hosni, H.M., Fayek, S.A., El-Sayed, S.M., Roushdy, M., Soliman, M.A.: Optical properties and DC electrical conductivity of Ge28-xSe72Sbx thin films. Vacuum. 81, 54-58 (2006)

Javed, A., Khan, N., Bashir, S., Ahmad, M., Bashir, M.: Thickness dependent structural, electrical and optical properties of cubic SnS thin films. Mater. Chem. Phys. 246, 122831 (2020)

Jia, T., Feng, Z., Guo, S., Zhang, X., Zhang, Y.: Screening promising thermoelectric materials in binary chalcogenides through high-throughput computations. ACS Appl. Mater. Interfaces. 12, 
Jrad, A., Naouai, M., Ammar, S., Turki-Kamoun, N.: Investigation of molybdenum dopant effect on $\mathrm{ZnS}$ thin films: Chemical composition, structural, morphological, optical and luminescence surveys. Mater. Sci. Semicond. Process. 130, 105825 (2021)

Kasap, S., Capper, P.: Springer handbook of electronic and photonic materials. Springer (2017)

Kathalingam, A., Valanarasu, S., Ahamad, T., Alshehri, S.M., Kim, H.-S.: Spray pressure variation effect on the properties of CdS thin films for photodetector applications. Ceram. Int. 47, 7608-7616 (2021)

Kumar, P., Sahariya, J., Soni, A., Bhamu, K.C.: Optoelectronic Analysis of CdGa2X4 (X= S, Se): A Promising Material for Solar Cells. In: Materials Science Forum. pp. 69-73. Trans Tech Publ (2017)

Liu, W.-S., Huang, C.-S., Chen, S.-Y., Lee, M.-Y., Kuo, H.-C.: Investigation of Cu2ZnSnS4 thin film with preannealing process and $\mathrm{ZnS}$ buffer layer prepared by magnetron sputtering deposition. J. Alloys Compd. 884, 161015 (2021)

Lougdali, M., Zazoui, M., Abboud, Y., Bouari, A.E.L., Zawadzka, A., Plociennik, P., Strzelecki, J., Strzałkowski, K., Migalska-Zalas, A., Waszkowska, K.: Linear and nonlinear optical properties of Manganese bis-(8-hydroxyquinoline) thin films for optoelectronic devices: experimental and computational studies. J. Mol. Struct. 131558 (2021)

Maiti, A., Chatterjee, S., Pal, A.J.: Sulfur-vacancy passivation in solution-processed Sb2S3 thin films: influence on photovoltaic interfaces. ACS Appl. Energy Mater. 3, 810-821 (2019)

Mane, R.S., Lokhande, C.D.: Chemical deposition method for metal chalcogenide thin films. Mater. Chem. Phys. 65, 1-31 (2000)

Manivannan, R., Victoria, S.N.: Preparation of chalcogenide thin films using electrodeposition method for solar cell applications-A review. Sol. Energy. 173, 1144-1157 (2018)

Merino, J.M., Leon, M., Rueda, F., Diaz, R.: Flash evaporation of chalcogenide thin films. Thin Solid Films. 361, 22-27 (2000)

Nagamalleswari, D., Kumar, Y.B.K., Ganesh, V.: Effect of substrate temperature on the growth of $\mathrm{CuSbS} 2$ thin films by chemical spray pyrolysis. Phys. B Condens. Matter. 616, 413119 (2021)

Orava, J., Kohoutek, T., Wagner, T.: Deposition techniques for chalcogenide thin films. In: Chalcogenide glasses. pp. 265-309. Elsevier (2014)

Patra, B.K., Khilari, S., Bera, A., Mehetor, S.K., Pradhan, D., Pradhan, N.: Chemically filled and Au-coupled BiSbS3 nanorod heterostructures for photoelectrocatalysis. Chem. Mater. 29, 1116-1126 (2017)

El Radaf, I.M., Al-Zahrani, H.Y.S., Hassanien, A.S.: Novel synthesis, structural, linear and nonlinear optical properties of p-type kesterite nanosized Cu2MnGeS4 thin films. J. Mater. Sci. Mater. Electron. (2020)(a). https://doi.org/10.1007/s10854-020-03369-9

El Radaf, I.M., AlKhalifah, M.S., El-Bana, M.S.: Structural, optical and optoelectrical analysis of a new window layer based on ZnAl 2 S 4 thin films. J. Mater. Sci. Mater. Electron. 1-13 (2020)(b)

El Radaf, I.M., Hameed, T.A., El komy, G.M., Dahy, T.M.: Synthesis, structural, linear and nonlinear optical properties of chromium doped SnO2 thin films. Ceram. Int. 45, 3072-3080 (2019). https://doi.org/10.1016/j.ceramint.2018.10.189

Rahman, M., Hossain, J., Kuddus, A., Tabassum, S., Rubel, M.H.K., Moriya, Y., Shirai, H., Ismail, 
A.B.M.: A novel CdTe ink-assisted direct synthesis of CdTe thin films for the solution-processed CdTe solar cells. J. Mater. Sci. 55, (2020)

Rahman, M.F., Moon, M.M.A., Ali, M.H., Ahmmed, S., Tabassum, S., Hossain, J., Ismail, A.B.M.: A systematic study of how annealing conditions lead to the application-based microstructural, crystallographic, morphological, and optical features of spin-coated CdS thin-films. Opt. Mater. (Amst). 117, 111136 (2021)

Sawant, J.P., Pathan, H.M., Kale, R.B.: Spray Pyrolytic Deposition of CuInS2 Thin Films: Properties and Applications. Eng. Sci. 13, 51-64 (2021)

Shaban, E.R., Ahmad, M., Wahab, E.A.A., Hassan, H.S., Aboraia, A.M.: Structural and optical properties of varies thickness of ZnTe nanoparticle. Angl. J. Assoc. English Lang. Am. Stud. 3, (2016)

Shakoury, R., Arman, A., Ţălu, Ş., Ghosh, K., Rezaee, S., Luna, C., Mwema, F., Sherafat, K., Salehi, M., Mardani, M.: Optical properties, microstructure, and multifractal analyses of ZnS thin films obtained by RF magnetron sputtering. J. Mater. Sci. Mater. Electron. 31, 5262-5273 (2020)

Sharma, D., Yadav, J., Mehta, B.R.: Reduced graphene oxide layer on nanostructured SnS thin films for improved visible light photoelectrochemical activity. Renew. Energy. 169, 414-424 (2021)

Sharma, I., Kumar, P., Tripathi, S.K.: Physical and optical properties of bulk and thin films of aGe-Sb-Te lone-pair semiconductors. Phase Transitions. 90, 653-671 (2017)

Sharma, P., Katyal, S.C.: Effect of tin addition on the optical parameters of thermally evaporated As-Se-Ge thin films. Mater. Chem. Phys. 112, 892-897 (2008)

Shi, S., Qian, S., Hou, X., Mu, J., He, J., Chou, X.: Structural and optical properties of amorphous Al2O3 thin film deposited by atomic layer deposition. Adv. Condens. Matter Phys. 2018, (2018). https://doi.org/10.1155/2018/7598978

Tauc, J., Grigorovici, R., Vancu, A.: Optical properties and electronic structure of amorphous germanium. Phys. status solidi. 15, 627-637 (1966)

Thangaraju, B., Kaliannan, P.: Polycrystalline lead tin chalcogenide thin film grown by spray pyrolysis. Cryst. Res. Technol. J. Exp. Ind. Crystallogr. 35, 71-75 (2000)

Verger, F., Nazabal, V., Colas, F., Němec, P., Cardinaud, C., Baudet, E., Chahal, R., Rinnert, E., Boukerma, K., Péron, I.: RF sputtered amorphous chalcogenide thin films for surface enhanced infrared absorption spectroscopy. Opt. Mater. Express. 3, 2112-2131 (2013)

Vinayakumar, V., Shaji, S., Avellaneda, D., Roy, T.K. Das, Castillo, G.A., Martinez, J.A.A., Krishnan, B.: CuSbS2 thin films by rapid thermal processing of Sb2S3-Cu stack layers for photovoltaic application. Sol. Energy Mater. Sol. Cells. 164, 19-27 (2017)

Wang, J., Jin, L., Wang, T., Zhao, L., Guan, F., Li, S., Wang, D., Zhang, J.: Length and composition tunable $\mathrm{Sb}-\mathrm{Bi}-\mathrm{S}$ nanowires for optoelectronic devices prepared via an isostructure-favored solvothermal synthesis. J. Alloys Compd. 831, 154886 (2020)(a)

Wang, L., Guan, Z., Tang, A.: Multinary copper-based chalcogenide semiconductor nanocrystals: synthesis and applications in light-emitting diodes and bioimaging. J. Nanoparticle Res. 22, 1-20 (2020)(b)

Wemple, S.H.: Refractive-index behavior of amorphous semiconductors and glasses. Phys. Rev. B. 7, 3767 (1973)

Wemple, S.H., DiDomenico Jr, M.: Behavior of the electronic dielectric constant in covalent and 
ionic materials. Phys. Rev. B. 3, 1338 (1971)

Wen, S., Zhao, J., Chen, J., Yang, J., Xu, J.: BiSbS $3 @$ N-doped carbon core-shell nanorods as efficient anode materials for sodium-ion batteries. Dalt. Trans. 48, 10448-10454 (2019)

Xie, S., Jin, H., Li, J., Wei, Y.: Promises of Main-Group Metal Chalcogenide-Based Broken-Gap van der Waals Heterojunctions for Tunneling Field Effect Transistors. ACS Appl. Electron. Mater. 3, 898-904 (2021)

Yang, G., Li, X., Ji, X., Xu, X., Wang, A., Huang, J., Zhu, Y., Pan, G., Cui, S.: Phase composition of the earth-abundant $\mathrm{Cu} 2 \mathrm{SnS} 3$ thin films with different annealing temperature and its effects on the performance of the related solar cells. Sol. Energy. 208, 206-211 (2020)

Yang, W., Zhang, X., Tilley, S.D.: Emerging Binary Chalcogenide Light Absorbers: Material Specific Promises and Challenges. Chem. Mater. (2021)(a)

Yang, Y., Shi, C., Lv, K., Wang, Q., Guo, F., Chen, W.: The low-temperature preparation for crystalline Sb2S3 thin films and photovoltaic performance of the corresponding solar cells. Sol. Energy. 217, 25-28 (2021)(b)

Zhang, J., Lian, W., Yin, Y., Wang, X., Tang, R., Qian, C., Hao, X., Zhu, C., Chen, T.: All Antimony Chalcogenide Tandem Solar Cell. Sol. RRL. 4, 2000048 (2020) 


\section{$\underline{\text { Table Captions }}$}

Table 1: The structural parameters of the $\mathrm{BiSbS}_{3}$ thin films.

Table 2: The optical parameters of the $\mathrm{BiSbS}_{3}$ thin films.

Table 3: The nonlinear optical constants of the $\mathrm{BiSbS}_{3}$ thin films.

\section{List of Tables}

Table 1: The structural parameters of the $\mathrm{BiSbS}_{3}$ thin films.

\begin{tabular}{|c||c|c||c||c||}
\hline Thickness (nm) & $D(\mathbf{n m})$ & $\boldsymbol{\varepsilon} \times \mathbf{1 0}^{-3}$ & $\delta \times \mathbf{1 0}^{-4}(\mathbf{n m})^{-2}$ & $\begin{array}{c}N_{C} \times \mathbf{1 0}^{-3} \\
(\text { line/nm }\end{array}$ \\
\hline \hline $\mathbf{1 5 9} \mathbf{~ n m}$ & 21.29 & 16.87 & 2.21 & 16.47 \\
\hline \hline $\mathbf{2 4 3} \mathbf{~ n m}$ & 25.85 & 13.49 & 1.49 & 14.06 \\
\hline $\mathbf{2 9 3} \mathbf{~ n m}$ & 34.46 & 10.15 & 0.84 & 7.23 \\
\hline $\mathbf{3 6 2} \mathbf{~ n m}$ & 39.26 & 8.385 & 0.65 & 5.98 \\
\hline
\end{tabular}

Table 2: The optical parameters of the $\mathrm{BiSbS}_{3}$ thin films.

\begin{tabular}{|c|c|c|c|c|c|c|c|c|}
\hline Thickness (nm) & $E_{g}^{d i r}(\mathrm{eV})$ & $E_{e}(e V)$ & $E_{d}(e V)$ & $E_{o}(e V)$ & $n_{o}$ & $\mathcal{E}_{s}$ & $\mathcal{E}_{L}$ & $\begin{array}{c}\mathrm{N} / \mathrm{m}^{*} \times 10^{46} \\
\mathrm{gm} / \mathrm{cm}^{3}\end{array}$ \\
\hline $159 \mathrm{~nm}$ & 1.38 & 0.76 & 8.54 & 2.22 & 2.21 & 4.85 & 9.74 & 4.98 \\
\hline $243 \mathrm{~nm}$ & 1.34 & 0.83 & 10.45 & 2.14 & 2.42 & 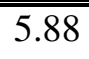 & 10.98 & 5.28 \\
\hline $293 \mathrm{~nm}$ & 1.29 & 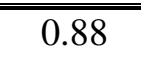 & $\bar{~} 11.28$ & 2.08 & 2.53 & $\bar{~} 6.42$ & 11.54 & 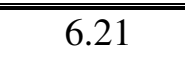 \\
\hline $362 \mathrm{~nm}$ & 1.22 & 0.91 & 12.64 & 1.97 & 2.73 & 7.41 & 12.32 & 7.57 \\
\hline
\end{tabular}


Table 3: The nonlinear optical constants of the $\mathrm{BiSbS}_{3}$ thin films.

\begin{tabular}{|c||c|c|c|}
\hline Thickness $(\mathbf{n m})$ & $\chi^{(\mathbf{1})}(\mathbf{e s u})$ & $\chi^{(3)} \times \mathbf{1 0}^{-12}(\mathbf{e s u})$ & $\boldsymbol{n}_{2} \times \mathbf{1 0}^{-11}(\mathbf{e s u})$ \\
\hline \hline $\mathbf{1 5 9} \mathbf{~} \mathbf{m}$ & 0.306 & 1.49 & 2.56 \\
\hline $\mathbf{2 4 3} \mathbf{~ m m}$ & 0.389 & 3.88 & 6.03 \\
\hline $\mathbf{2 9 3} \mathbf{~ n m}$ & 0.431 & 5.90 & 8.78 \\
\hline $\mathbf{3 6 2} \mathbf{~} \mathbf{m}$ & 0.510 & 11.57 & 16.01 \\
\hline
\end{tabular}




\section{$\underline{\text { Figure caption }}$}

Fig. (1): The X-ray investigations of the $\mathrm{BiSbS}_{3}$ films with various thicknesses $(\mathrm{t}=159,243,296$ and $362 \mathrm{~nm})$.

Fig. (2): The dependence of $D$ and $N_{C}$ of the chemically deposited $\mathrm{BiSbS}_{3}$ films on the film thickness.

Fig. (3): (a) The FE-EM image and EDAX spectrum of the $\mathrm{BiSbS}_{3}$ thin films with thickness $159 \mathrm{~nm}$,

(b) The FE-EM image and EDAX spectrum for the $\mathrm{BiSbS}_{3}$ thin films with thickness $362 \mathrm{~nm}$.

Fig. 4: (a) The transmittance spectra of the $\mathrm{BiSbS}_{3}$ thin films versus the wavelength $(\lambda)$, (b) reflectance spectra of the $\mathrm{BiSbS}_{3}$ thin films versus the wavelength $(\lambda)$.

Fig. 5: (a) The variation of the absorption coefficient $(\alpha)$ chemically prepared $\mathrm{BiSbS}_{3}$ thin films with the wavelength $(\lambda)$, (b) The plot of the $(\alpha h v)^{2}$ versus $h v$ for the $\mathrm{BiSbS}_{3}$ films.

Fig. 6: (a) The variation of $\ln (\alpha)$ versus $h v$ for the chemically prepared $\mathrm{BiSbS}_{3}$ films, (b) The extinction coefficient $(k)$ of the $\mathrm{BiSbS}_{3}$ films versus the wavelength $(\lambda)$.

Fig. 7: (a) The refractive index ( $n$ ) of the $\mathrm{BiSbS}_{3}$ films versus the wavelength $(\lambda)$, (b) The alteration of the $\left(n^{2}-1\right)^{-1}$ versus $(h v)^{2}$ for the chemically prepared $\mathrm{BiSbS}_{3}$ films.

Fig.8: (a) and (b) The variations of $\varepsilon_{1}$ and $\varepsilon_{2}$ for the chemically prepared $\mathrm{BiSbS}_{3}$ films with the wavelength $(\lambda)$.

Fig. 9: (a) A plot of $\sigma_{\text {opt }}$ against $h v$ for the $\mathrm{BiSbS}_{3}$ films, (b) the variation of $n^{2}$ versus $\lambda^{2}$ for the chemically prepared $\mathrm{BiSbS}_{3}$ films.

Fig. 10: The dependence of the $\chi^{(3)}$ and $n_{2}$ on the film thickness of the chemically prepared $\mathrm{BiSbS}_{3}$ films.

Fig. 11: The hot-probe procedure applied on the chemically prepared $\mathrm{BiSbS}_{3}$ films. 
Fig. (1):

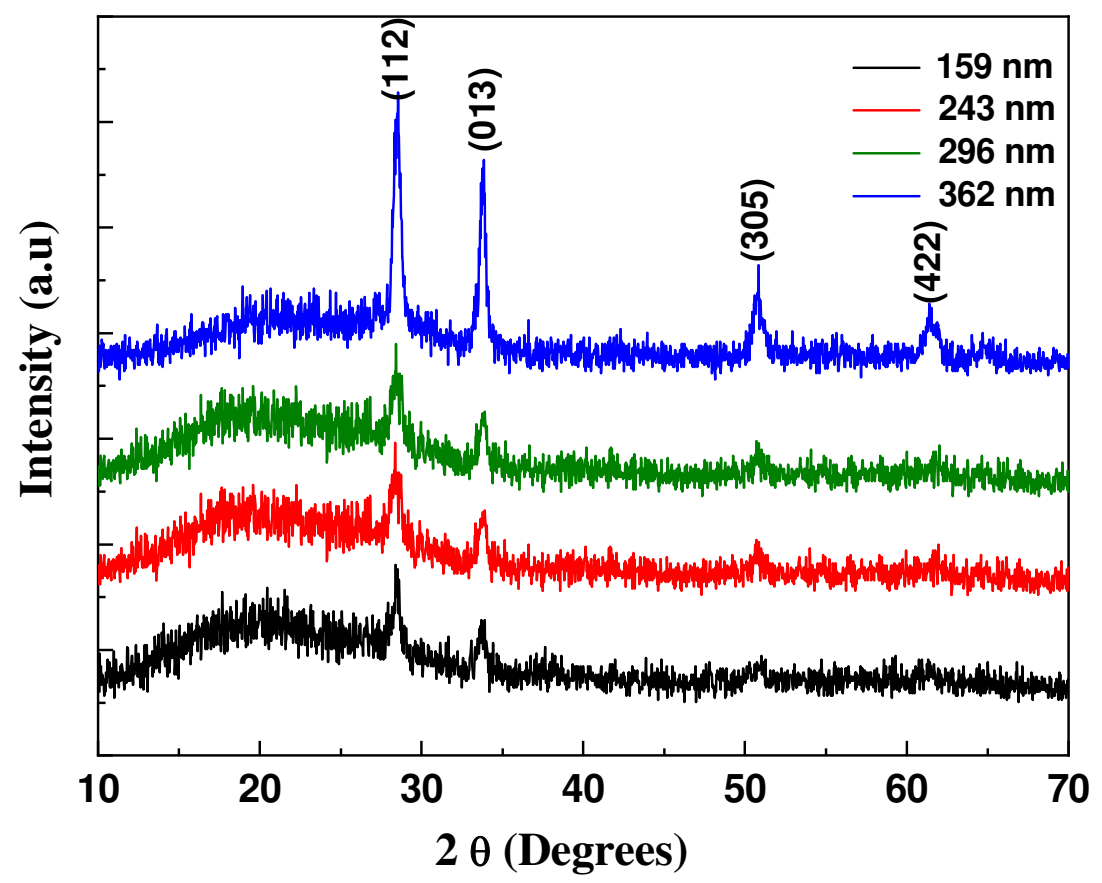

Fig. (1): The X-ray investigations of the $\mathrm{BiSbS}_{3}$ films with various thicknesses $(\mathrm{t}=159,243,296$ and $362 \mathrm{~nm})$.

Fig. (2):

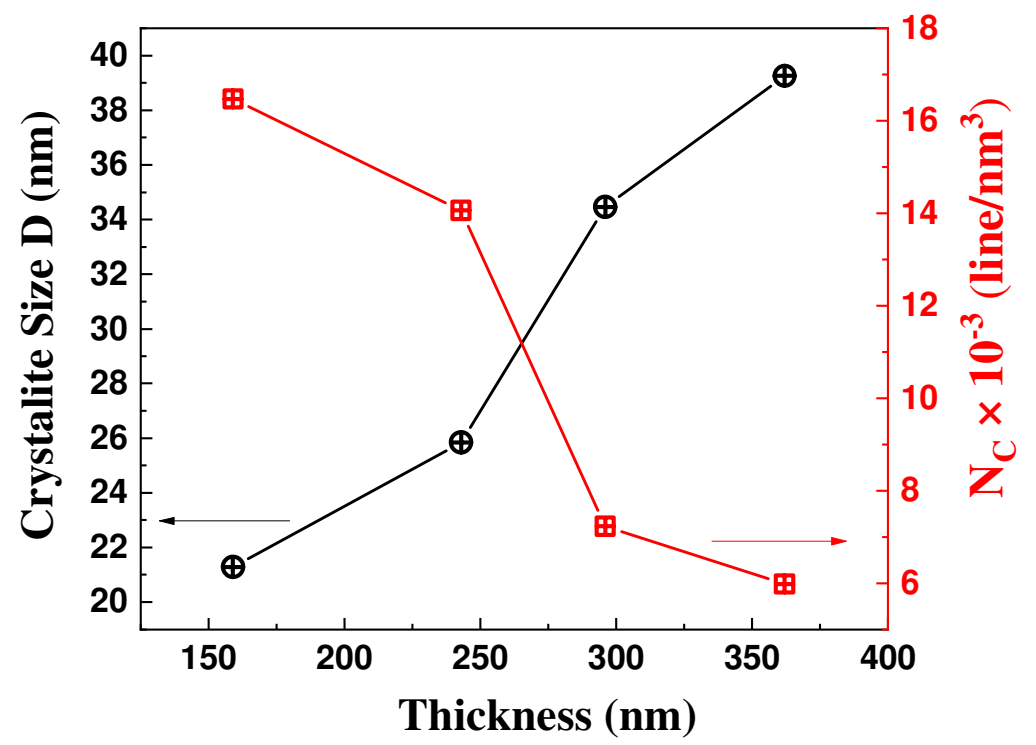

Fig. (2): The dependence of $D$ and $N_{C}$ of the chemically deposited $\mathrm{BiSbS}_{3}$ films on the film thickness. 
Fig. (3):
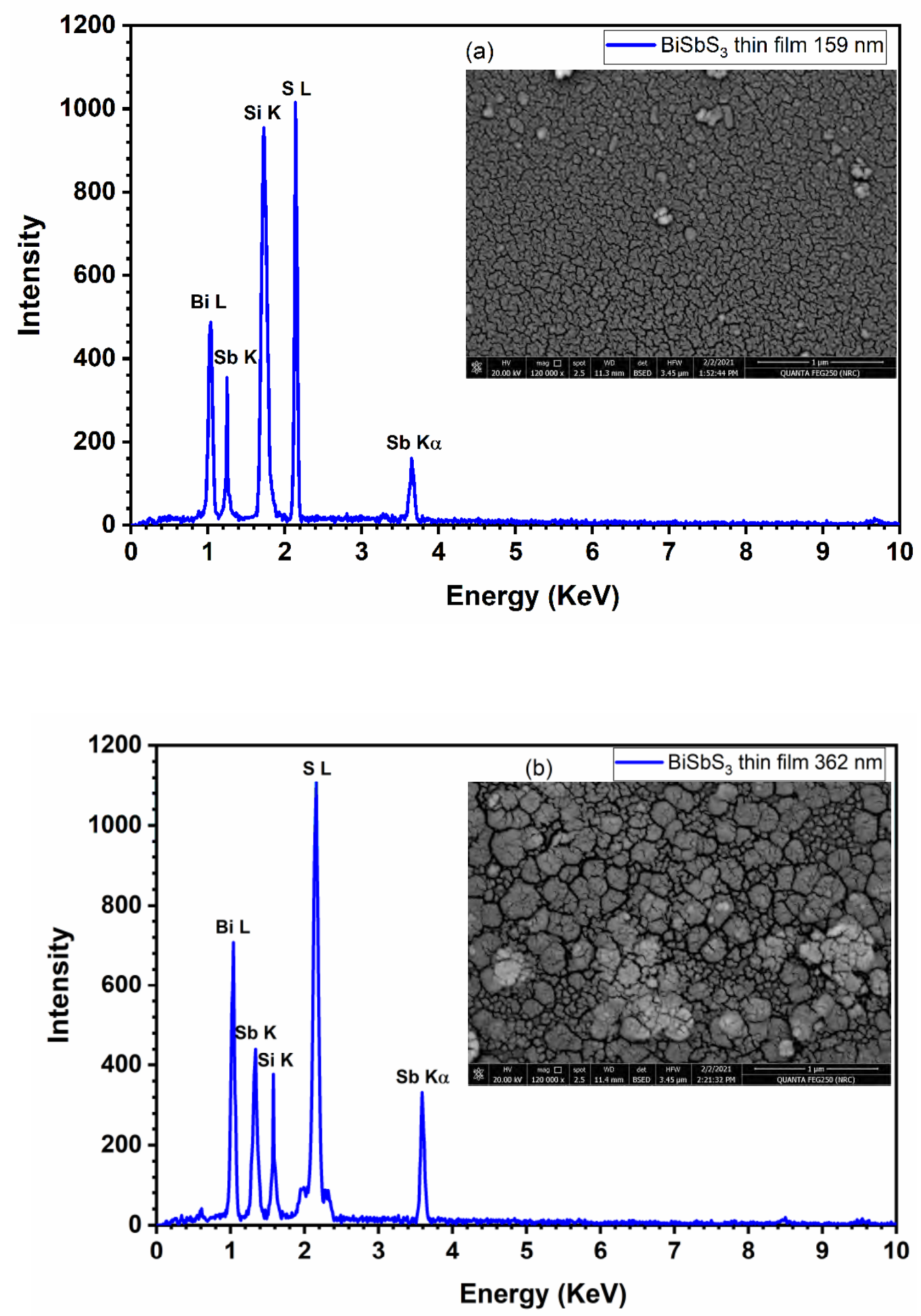

Fig. (3): The FE-EM micrographs and EDAX spectra for the $\mathrm{BiSbS}_{3}$ thin films with thickness $159 \mathrm{~nm}$, (b) The FE-EM micrographs and EDAX spectra for the $\mathrm{BiSbS}_{3}$ thin films with thickness $362 \mathrm{~nm}$. 
Fig. (4):
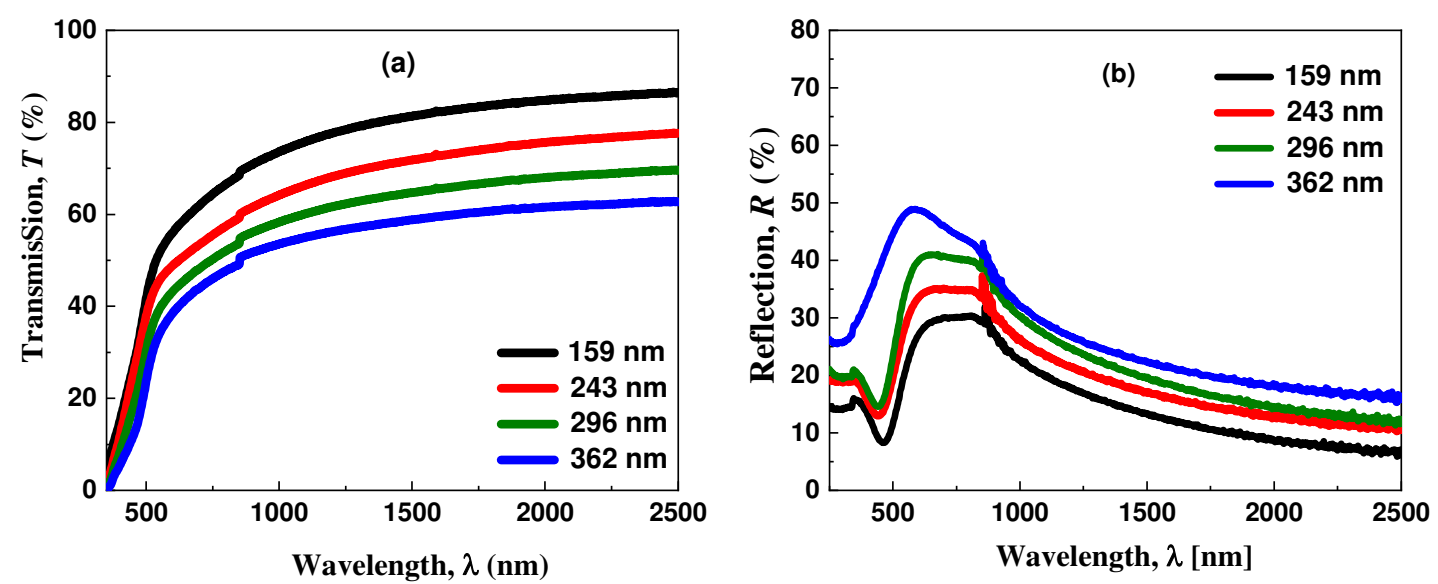

Fig. 4: (a) The transmittance spectra of the $\mathrm{BiSbS}_{3}$ thin films versus the wavelength $(\lambda)$, (b) reflectance spectra of the $\mathrm{BiSbS}_{3}$ thin films versus the wavelength $(\lambda)$.

Fig. (5):
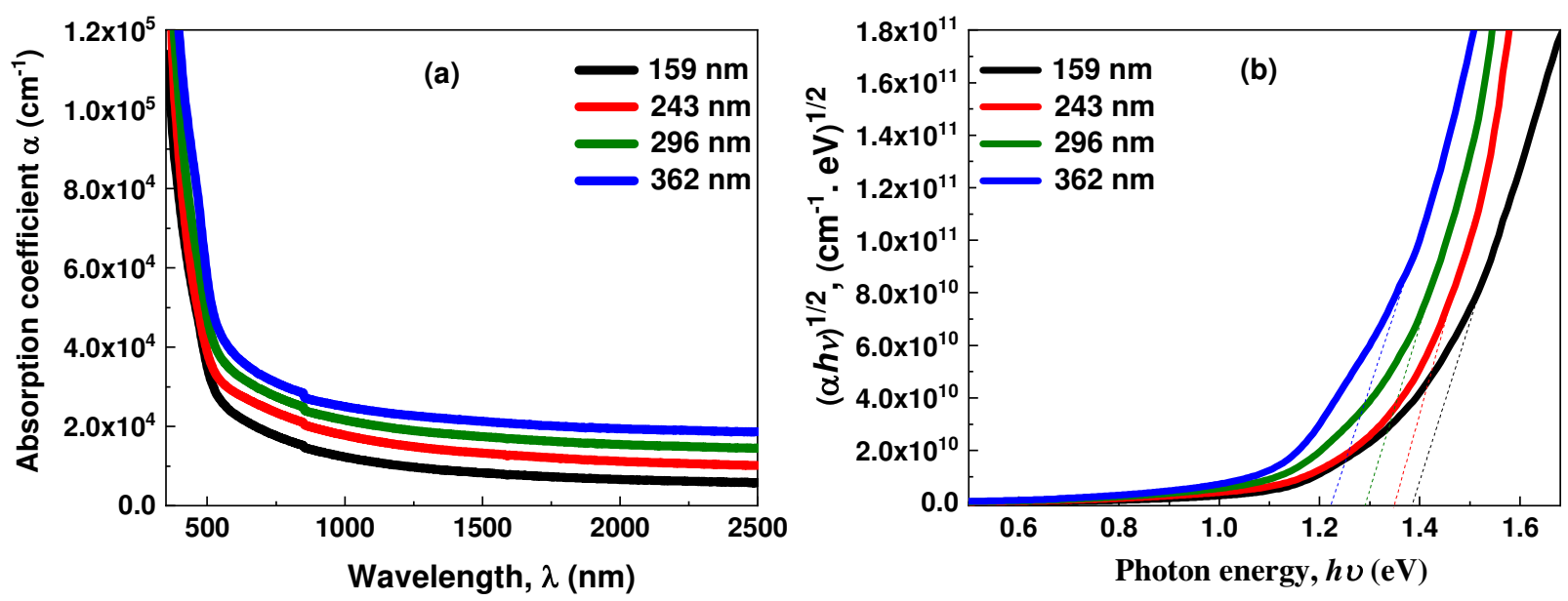

Fig. 5: (a) The variation of the absorption coefficient $(\alpha)$ chemically prepared $\mathrm{BiSbS}_{3}$ thin films with the wavelength $(\lambda)$, (b) The plot of the $(\alpha h v)^{2}$ versus $h v$ for the $\mathrm{BiSbS}_{3}$ films. 
Fig. (6):
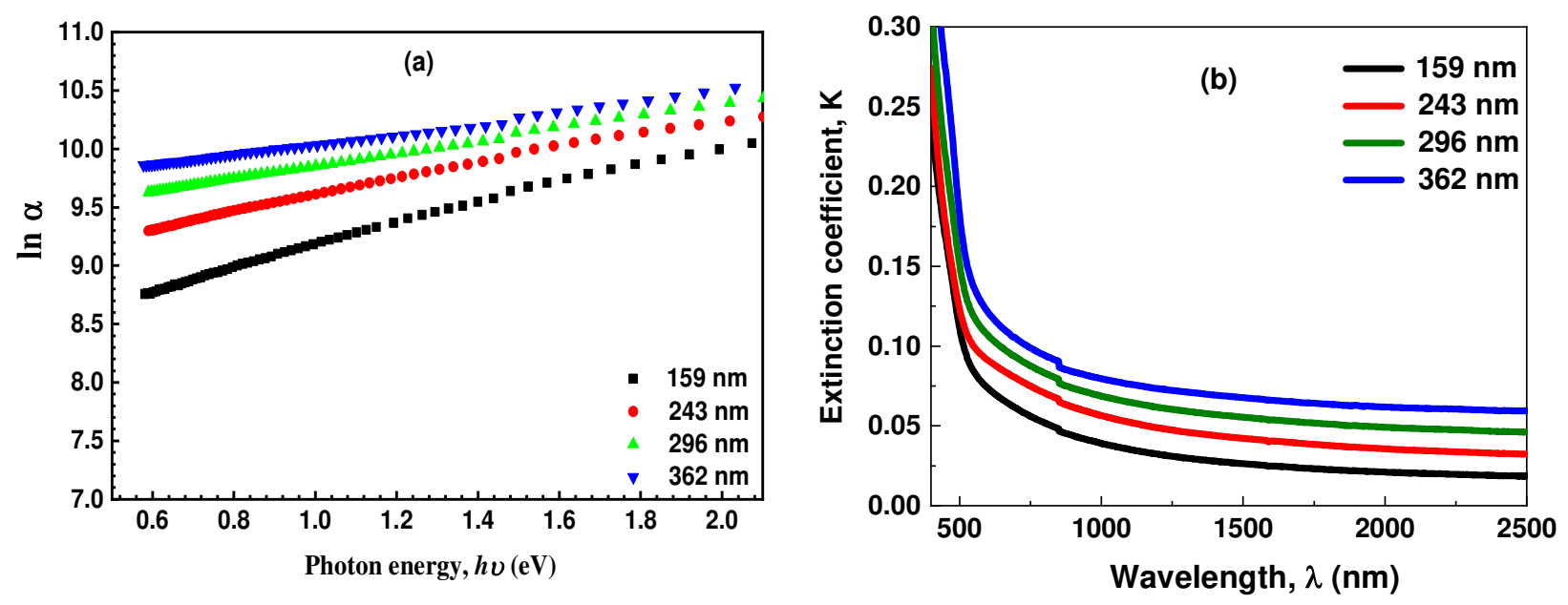

Fig. 6: (a) The variation of $\ln (\alpha)$ versus $h v$ for the chemically prepared $\mathrm{BiSbS}_{3}$ films, (b) The extinction coefficient $(k)$ of the $\mathrm{BiSbS}_{3}$ films versus the wavelength $(\lambda)$.

Fig. (7):
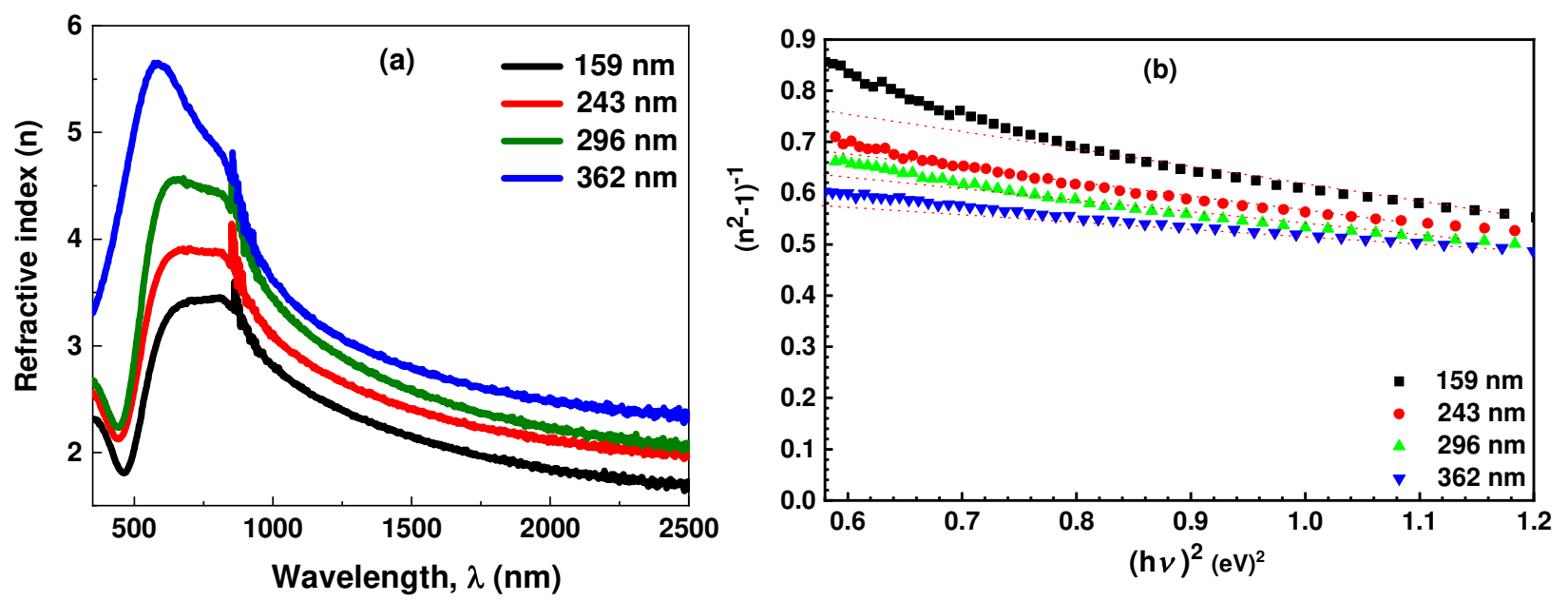

Fig. 7: (a) The refractive index ( $n$ ) of the $\mathrm{BiSbS}_{3}$ films against the wavelength $(\lambda)$, (b) The alteration of the $\left(n^{2}-1\right)^{-1}$ versus $(h \nu)^{2}$ for the chemically prepared $\mathrm{BiSbS}_{3}$ films. 
Fig. (8):
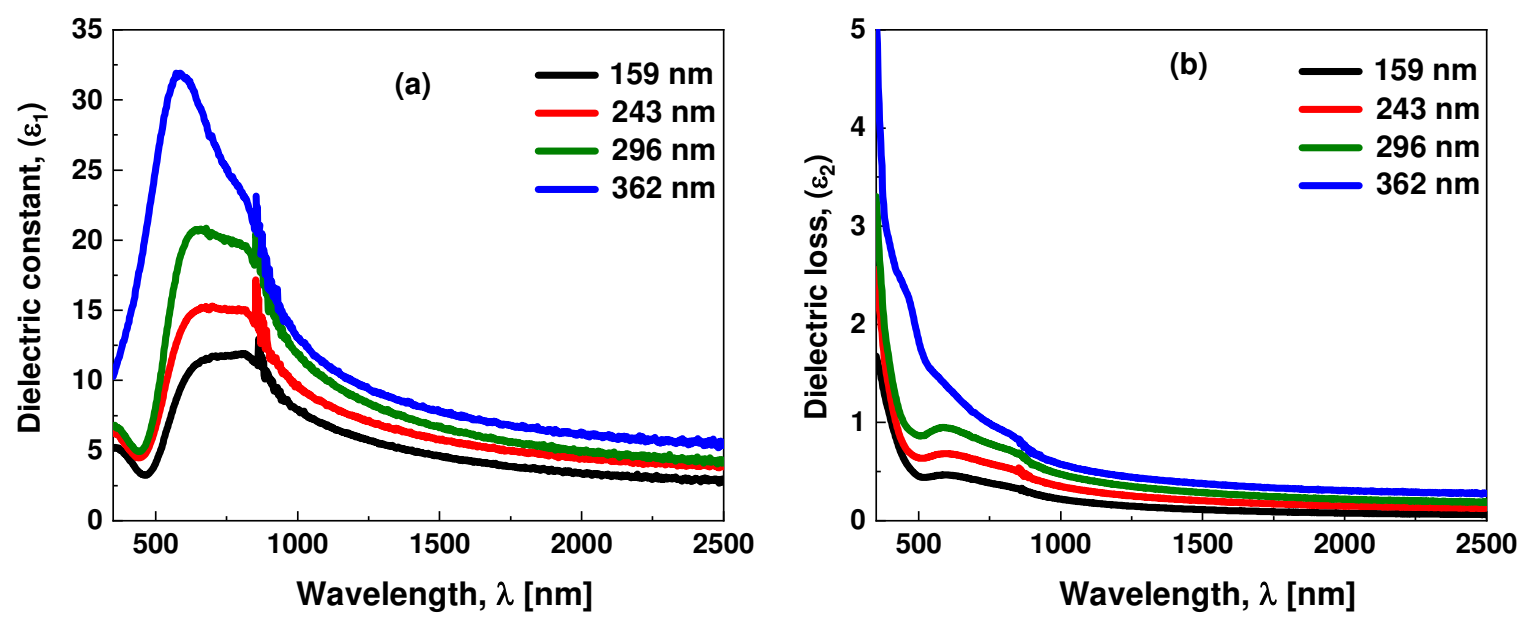

Fig.8: (a) and (b) The variations of $\varepsilon_{1}$ and $\varepsilon_{2}$ for the chemically prepared $\mathrm{BiSbS}_{3}$ films with the wavelength $(\lambda)$.

Fig. (9):
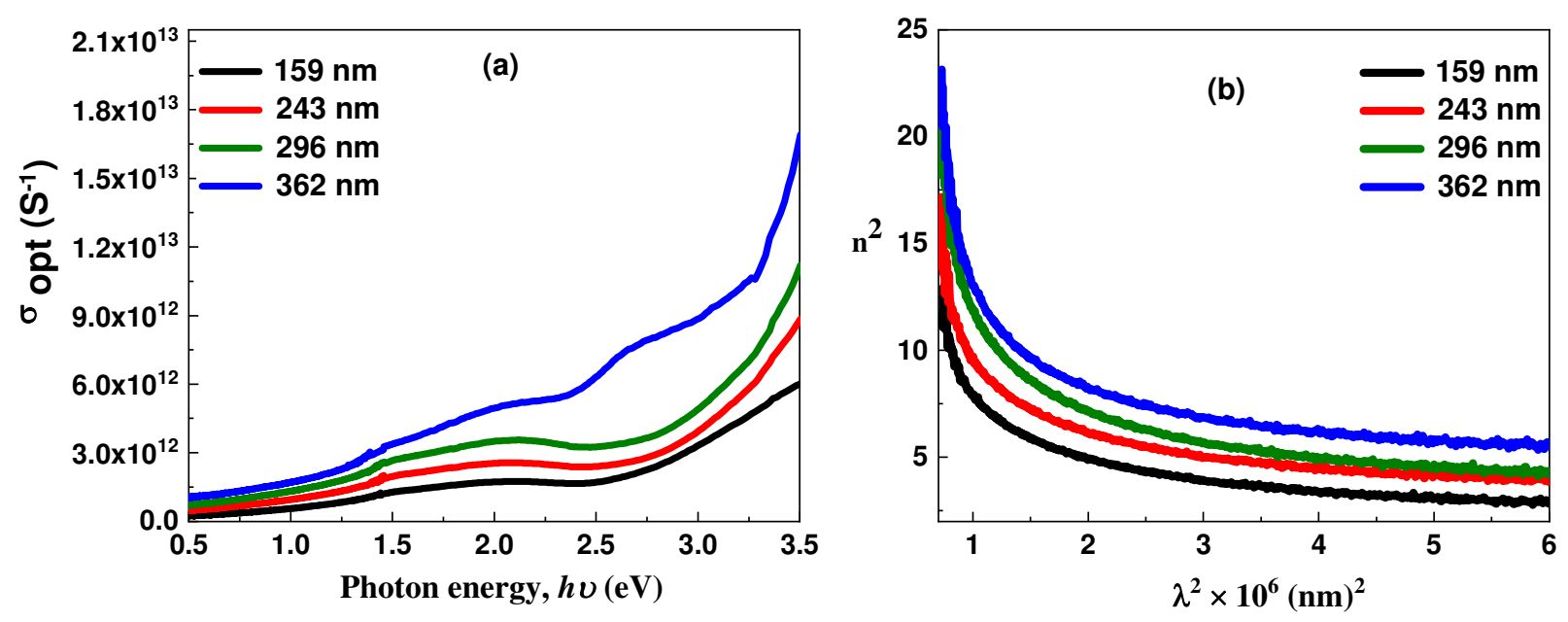

Fig. 9: (a) A plot of $\sigma_{o p t}$ against $h v$ for the $\mathrm{BiSbS}_{3}$ films, (b) the variation of $n^{2}$ versus $\lambda^{2}$ for the chemically prepared $\mathrm{BiSbS}_{3}$ films. 
Fig. (10):

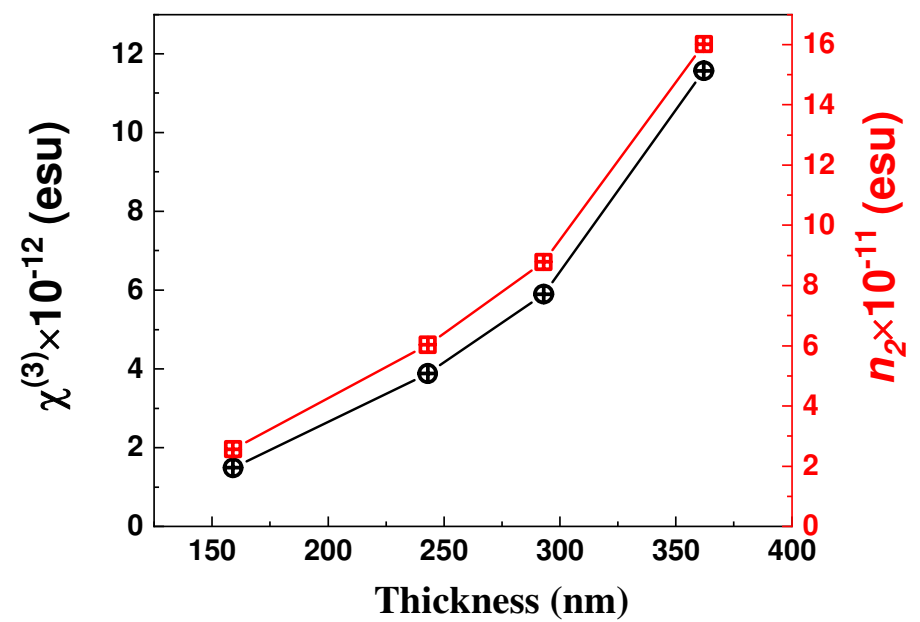

Fig. 10: The dependence of the $\chi^{(3)}$ and $n_{2}$ on the film thickness of the chemically prepared $\mathrm{BiSbS}_{3}$ films.

Fig. (11):

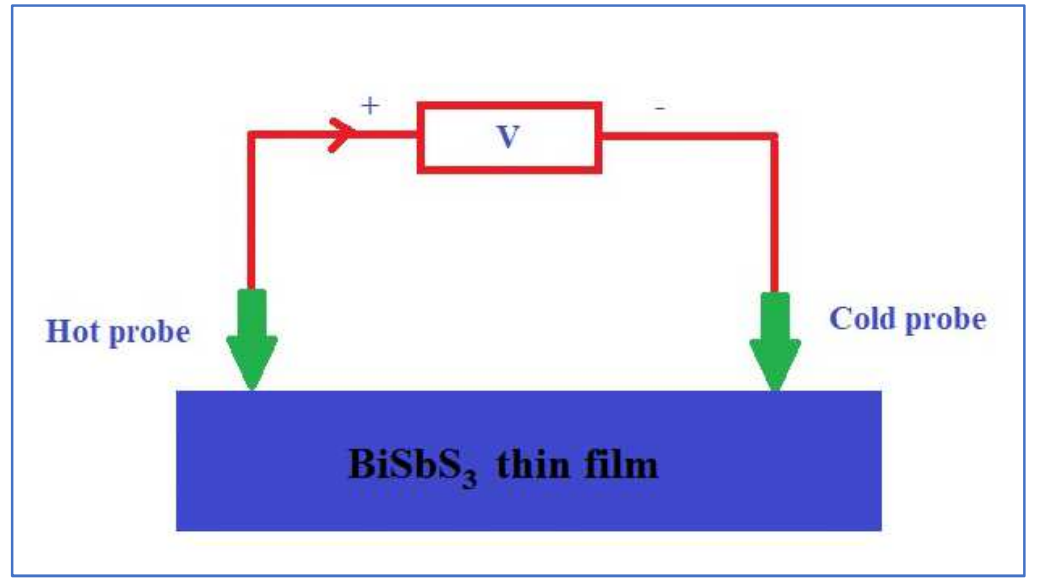

Fig. 11: The hot-probe procedure applied on the chemically prepared $\mathrm{BiSbS}_{3}$ films. 